\title{
A CONTENT-BASED IMMERSIVE EXPERIENCE OF BASILICA OF SANT'AMBROGIO IN MILAN: FROM 3D SURVEY TO VIRTUAL REALITY
}

\author{
F. Banfi ${ }^{1 *}$, R. Brumana ${ }^{1}$, C. Stanga ${ }^{2}$ \\ ${ }^{1}$ Dept. of Architecture, Built Environment and Construction Engineering, 20133 Milan, Italy - \\ (raffaella.brumana; fabrizio.banfi)@polimi.it \\ ${ }^{2}$ Dept. of Architecture and Urban Studies, 20133 Milan, Italy - chiara.stanga@polimi.it
}

Commission WG II/8, WG III/5, WG V/1

KEY WORDS: Scan-to-BIM, Grade of Generation (GOG), HBIM, Virtual Reality, eXtended Reality, Interactivity

\begin{abstract}
:
One of the challenges of the Digital Cultural Heritage (DCH) field is the creation of coherent HBIMs and the dissemination of the collected historical data. The latest development of new technologies has the great potential to realise virtual content-based immersive experiences that are easily available by both experts and non-expert users. On the other hand, they require specific skills and a holistic approach to the study of the building that involves different disciplines.

The research that has been carried out for the last five years on one of the greatest monuments in Milan, the Basilica of Sant'Ambrogio, adopted this comprehensive methodology. Although the church is a very well-known building, its turbulent history remains in a certain aspect hidden to the large public. This paper shows the workflow that has been developed for the Basilica, starting from the 3D survey to the historical data acquisition and the study on the church itself, based on a 'virtual subtraction process', till the creation of a Virtual Reality experience. This one is the first step of a wider project on eXtended reality (Virtual/Mixed/Augmented Reality) that intends to make the gathered knowledge of the Basilica available to the public.
\end{abstract}

\section{INTRODUCTION}

In recent years, the use of digital technologies for Built Heritage recording has greatly expanded. The integrated use of laser scanning and digital photogrammetry are allowing holistic management of unique artefacts, through Building Information Modeling for heritage buildings (HBIM), supporting different types of BIM-based activities such as restoration, maintenance, structural analysis, computing and facility management (Tucci et al., 2016). This specific integration of devices, innovative methods and advanced technologies in the field of Digital Cultural Heritage (DCH) are well known as the Scan-to-BIM process (Brumana et al., 2018). Recent studies have shown how the intangible and tangible values of detected heritage artifact can be shared and transmitted to different professionals and users with high levels of detail (LOD) and contents (LOI), going beyond the simple 2D representation and the simple use of BIM objects and BIM libraries developed for new buildings (Ortega et al., 2015; Statham, 2019). Thanks to previous researches (Banfi et al., 2019; Stanga et al., 2017), the presented paper offers a new virtual environment, based on the use of 'informative models', that communicates the 'hidden' values collected during the last few years of one of the most important monuments in Milan: the Basilica of Sant'Ambrogio.

\section{RELATED WORKS AND RESEARCH OBJECTIVES}

Starting from the introduction of new digital advanced techniques, surveying and architectural disciplines are facing new challenges in the field of the Digital Cultural Heritage (DCH). One of the main challenges is related to find new balances between the great amount of data collected during the $3 \mathrm{D}$ survey and the historical research, and the new ways of dissemination, supported by the development of new technologies and virtual environments (e.g., AR, VR), shared among expert and not-expert visitors/users of heritage buildings.

The application of Virtual Reality to the Cultural Heritage is not a completely new issue and it is related to the development of different kind of experiences, where the main goal is to share historical knowledge through different devices and media, considering the 'edutainment' (education + entertainment) aspects, like serious, puzzle and trivia games (for a State of the Art see: Falk Anderson et al., 2009; Mortara et al., 2014). Recent studies are going through this topic, trying not to 'trivialize' the historical content with simplistic approaches, but using the potentiality of the new technologies to boost and hand down the complex history of the detected building, with its tangible and intangible values.

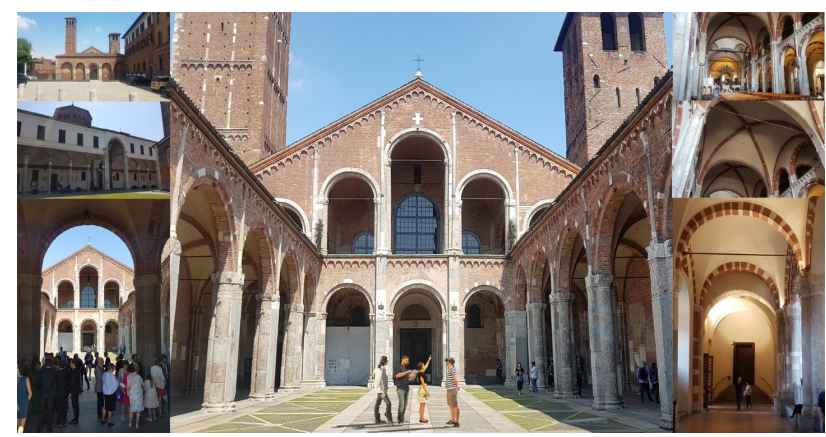

Figure 1. The Basilica of Sant'Ambrogio and its distinctive architectural elements that add prestige to the image of the city of Milan.

* Corresponding author 
Those researches are usually carried out by a great number of experts (architects, engineers, restorers, BIM operators, art and architecture historians, ...), working in teams, which highlights the important value of a holistic approach when dealing with the transmission of the rich knowledge of the Built Heritage.

Some examples adopted these new technologies for a critic analysis of complex architectural systems, of their conservation and management, like the research on the Castel Nuovo in Naples (cooperation of the Ministry of Culture, the Federico II University of Naples and the Alta Tecnologia per i Beni della Regione Campania District) (Amore, 2017; Aveta et al., 2017). Others are focused on the dissemination of historical information, like the project of the Palermo Cathedral, based on VR application (Unreal Engine) (Agnello et al., 2019) or the Castle of Lecce (funded by European grants), for which different exhibition staging has been realised: traditional panels, educational video clips, historical reconstructions, together with totem, multimedia guides, 3D viewer and a docufiction (Cacudi, 2018). These few examples show how our approach to the Built Heritage is quickly changing, supported by the integration of different disciplines and the development of new technologies.

In the case of the Basilica of S. Ambrogio in Milan, through Virtual Reality, it has been possible to share the acquired information with a wider public. Moreover, although the basilica is a well-known building and Archbishop Ambrogio is one of the most significant historical and religious figures in the history of Milan and Christianity, some events are still not so valued.

This study shed further lights on the construction of the basilica itself, demonstrating how, even in the case of such a well-known building, new perspectives and new tools can still reveal original building features. Buildings do not have one coherent history but have many histories that mirror the past historical and natural events. That is why this research wants to highlight and interpret the different histories rather than the history of the basilica, showing the complexity that characterised it.
The goal of the research can be summarised as follow:

- To document, with advanced survey techniques, the Basilica of S. Ambrogio in Milan - the church, its side chapels, the crypt, the ancient S. Vittore in Ciel d'Oro chapel, the Bramante's Canonica, the foursided portico and the two bell towers (an accurate laser scanning survey hadn't existed until this study);

- To improve the generative modeling by the use of novel grade of generation (GOA) and accuracy (GOA) for scan-to-BIM models;

- To create an informative model (HBIM) that can offer a tool for the management of the church and that can be used for further developments for touristic purposes;

- To find a balance between the great amount of the acquired data (3D survey, historical analysis), the accuracy of the HBIM and the management of the database that collects the information;

- To develop an immersive experience, through the use of HBIM for a Virtual Reality project (Unreal Engine) in order to improve the visitors' experience of the Basilica, showing the acquired knowledge;

- To improve the new paradigm of interactivity between users and VR objects, adding support for Motion Controller Component Setup for a different type of platforms (Android, iOS Game development, Google VR, Oculus Rift, Samsung Gear VR, Virtual Reality Oculus Rift, ...). This step includes the selection of the information, the design of the visitor's pathway and the creation of the interactive environment.

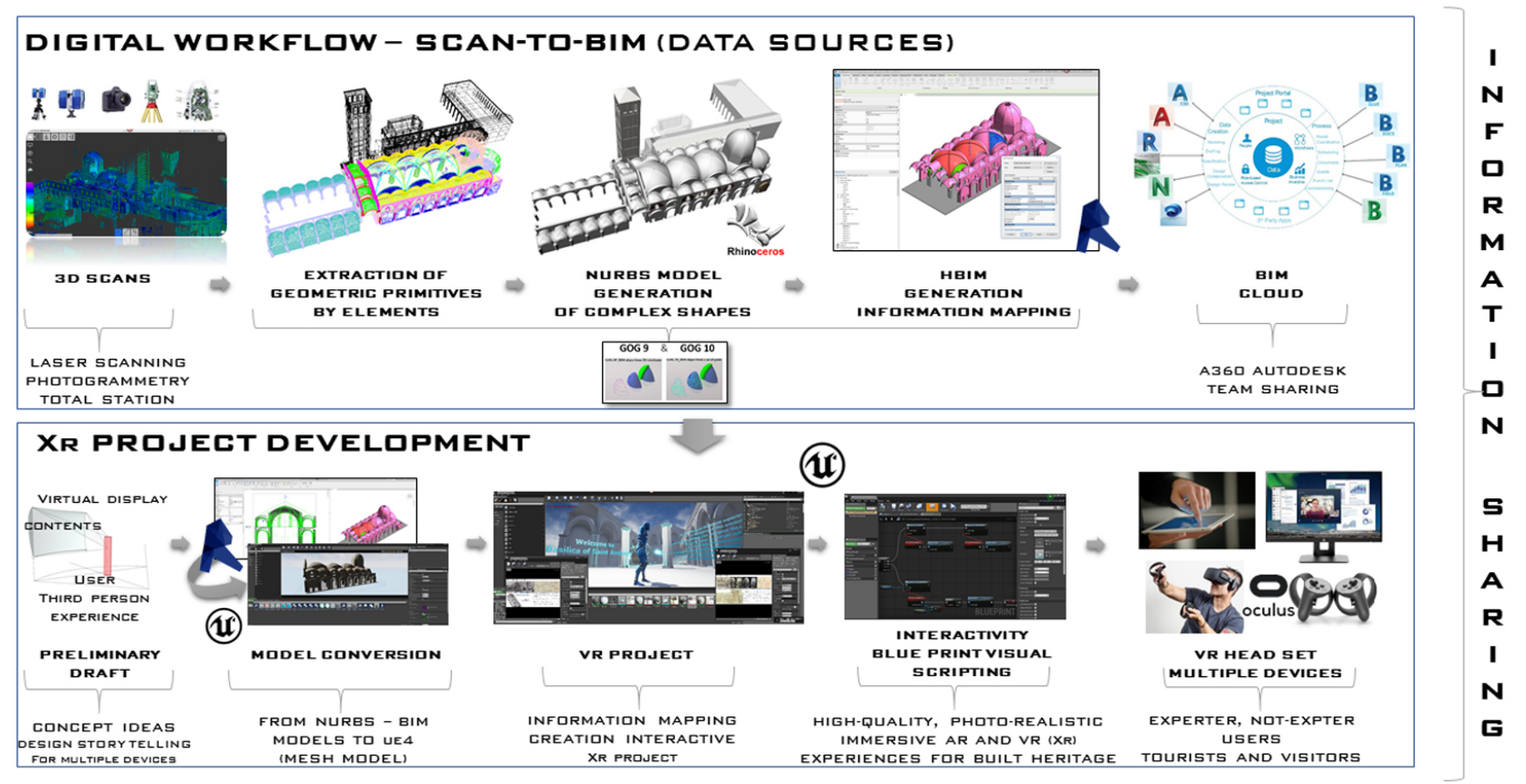

Figure 2. The Xr project development process. 


\section{RESEARCH METHODOLOGY}

The role of Milan as the capital of the Western Roman Empire (286-402 d.C.), under Saint Ambrogio (Aurelius Ambrosius, Treviri, 339-340 - Milan, 397), bishop of Milan, together with his huge Basilicas project, is mostly unknown, even if the celebration of Saint Ambrogio in the yearly Feast on the $7^{\text {th }}$ of December, patron of the city of Milan, still testifies the important past and present that has to be preserved for the future generations. In view of the Milan Winter Olympic Games IT candidature, the project is addressed to start providing an Xr (eXtended Reality/Mixed Reality/Augmented Reality) prototype, experimenting the valorization of HBIM data management within a Geographic contextualization aiming to communicate the unknown role of Milan when bishop Saint Ambrogio started the construction of the Basilica. Accordingly, a great effort has been made in the reconstruction of the HBIM of the Basilica of Sant'Ambrogio, and related information mapping, that risk to remain unknown. The research applies an interdisciplinary approach to the study of the tangible (materials, construction techniques) and intangible (its turbulent history) aspects of the Basilica, which includes survey advanced techniques and historical research. Those two elements are strictly intertwined in the research: one supports the other and vice versa.

\subsection{D and photogrammetric survey}

The first step into the knowledge of a heritage building is the understanding of its physical aspects (geometry and dimensions) and historical background (construction phases and transformation). These two tasks were performed through a field campaign using topographical, laser scanning and photogrammetric supports, and through literature review and archive research. The geometrical survey was carried out in two different phases. The first phase (2014) included the interior space of the church with its side chapels and matronei, the four-side portico and the Bramante's Canonica (outside). The geodetic network was measured with Total Station Leica TS30, and the scan acquisition was carried out with Faro Focus 3D. The second stage (2015) regarded the upper rooms of Bramante's Canonica with the double-curved wall and the S. Vittore in Ciel d'Oro chapel (interior space, outside and the crypt). A photogrammetric survey was carried out for the church aisles and the double-curved wall in order to gain the orthomosaics of for each chapels front and of each part of the arch structure (arch and pillar, side and front walls and arch intrados). The 3D scans were used as the basis for the traditional 2D drawing and HBIM, while the orthomosaics were used for the detailed Building Archaeology analysis of the basilica.

A large amount of data produced by the laser scanning acquisition phase required post-processing that orients and cleans the point cloud for the proper extraction of geometric primitives. This step was crucial to process the right amount of point of each 3D scan. In particular, thanks to new postprocessing functions in Autodesk Recap Pro it was possible to reduce the quantity of point for every spatial coordinate (x-y$\mathrm{z}$ ) and prepare the right bases for the modeling phase. The reduction and cleaning of $3 \mathrm{D}$ survey data allow the proper application of novel grade of generation (GOG) and accuracy (GOA) for the generation of detailed 3D building components (architectural and structural elements) corresponding to the detected reality. Figure 3 shows the post-processing phase applied to the point cloud data and the automatic reduction of point

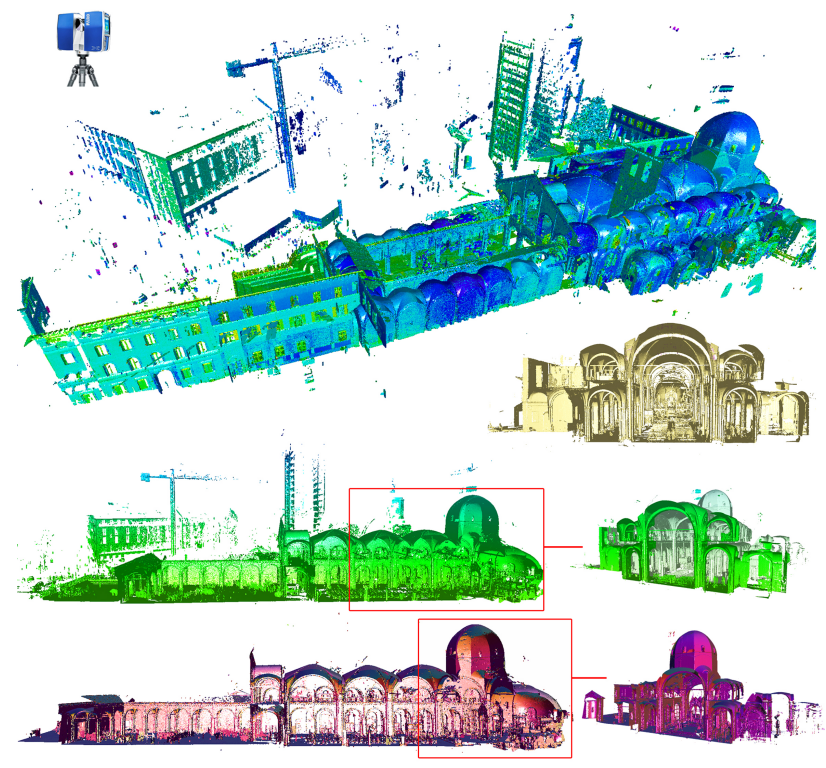

Figure 3. The post-processing phase: orientation, cleaning and creation of different layers of point cloud data for the generative process of scan-to-BIM elements.

\subsection{Generative modeling based on the novel grade of generation (GOG) and accuracy (GOA) for scan-to-BIM models}

Different data sources have been used to create a detailed HBIM model. Point cloud data from laser scanning and digital photogrammetry (primary data sources) and historical reports, material analysis, and 2D drawings (secondary data sources) have been used in order to improve the informative value of the model. In this context, as we well know, BIM software is not oriented to create complex models from point cloud data. The limited modeling toolset supports the creation of simple BIM objects such as walls, doors, floors, roofs, and windows that are included in BIM libraries.

Accordingly, BIM software represents the first gap in the generation of unique HBIM objects of heritage buildings. Heritage artefacts need unique BIM object orient to represent architectural and structural elements not included in BIM libraries such as vaults, irregular walls, decorations, arches and pillars. For this reason, the generative process of Basilica has been supported by the integrated use of novel grades of generation (GOG) able to create and geometric primitives and accurate digital models from point cloud data (Banfi, 2017).

Nowadays, as we well know, Autodesk Revit is known as the main application that realises BIM and automatically generates databases connected to the three-dimensional objects. One of the most critical barriers in BIM software is given by the lack of modeling tools able to directly use of 3D scans. On the other hand, this BIM software does not have internal functionalities that create complex objects like the Non-Uniform Rational Basis-Splines (NURBS) algorithms. Thanks to the use of GOG 9 and GOG 10 it has been possible to improve the generative process of complex architectural and structural elements using NURBS algorithms within the BIM software and to avoid drastic modeling simplification. The flexibility of the method is based on a free identification of the points for the automatic or semi-automatic extraction of geometrical primitives useful for the generation of digital models able to keep unaltered the real geometries of the surveyed buildings. In particular, GOG 10 is a modeling 
procedure that generates a NURBS model from a set of point automatically. It allowed the generation of irregular shapes by interpolating a closed exterior edge and a set of internal control points (Fig. 4).

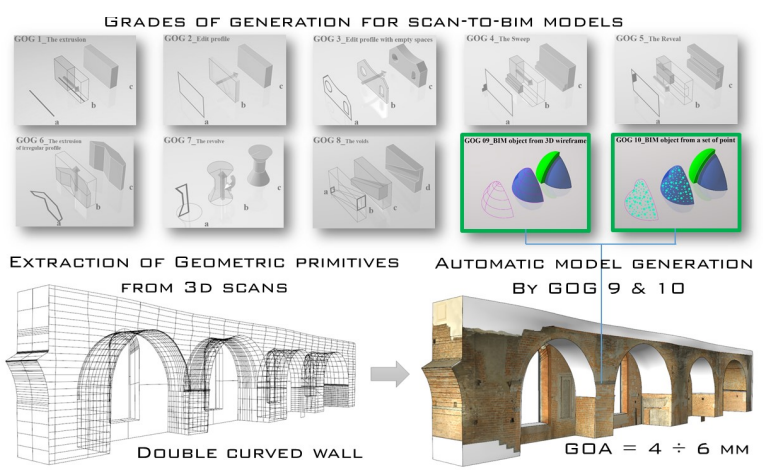

Figure 4. The application of GOG 9 and 10 for the most complex structural element of the Basilica of Sant Ambrogio.

As a consequence, before carrying out this transformation from NURBS to BIM object, the analysis of the surfaces has been analysed in order to improve a system that certifies the quality of the model. For this reason, thanks to the analysis of the surface curvature, an automatic verification system (AVS) has been identified to calculate the grade of accuracy (GOA) and to provide the value of the standard deviation between NURBS surface and 3D scan. Once verified the quality of the NURBS model, it was imported into Autodesk Revit. Thanks to the modeling requirements described in Banfi, F. BIM Orientation: Grades Of Generation And Information For Different Type Of Analysis And Management Process it has been possible to transform a NURBS model into a BIM object and consequently enable the information mapping typical of Autodesk Revit. This procedure ensured to preserve all the geometric anomalies of each architectural and structural element in HBIM and to link a great quantity of information to every single $3 \mathrm{D}$ object at the same time. As shown in figure 5 , the bidirectional relationship established between HBIM objects and information allowed to edit, import, link, and update new descriptive and numeric fields. GOG 10 has also given the opportunity to investigate a new type of sub-HBIM objects and improve the information sharing among different users using a BIM cloud system, moving from a simple 3D representation to a detailed HBIM model able to holistically support the preservation process.

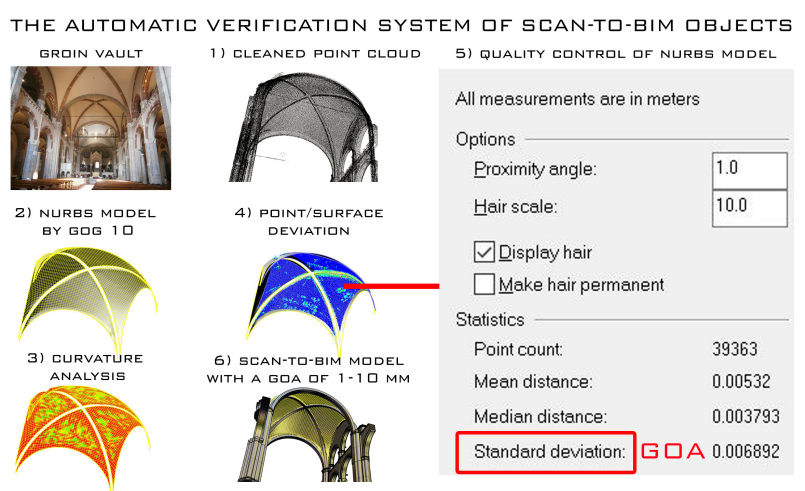

Figure 5. The AVS allowed the quality control of the model. The GOA achieved for every single groin vault was $1-10 \mathrm{~mm}$.
3.3 Building Information Modeling for heritage buildings (HBIM): from geometric primitives to 'informative' models

When we talk about HBIM models, we should consider a holistic approach able to support different type of BIM-based analysis. In the last five years, impressive research has shown how it has been possible to support and improve specific analysis.

The ability of HBIM, therefore, should consider different aspects such as the levels of detail (LOD), the grades of accuracy (GOA), 3D exchange formats for a different type of software and modeling logics. In this specific context, the proposed workflow considers and processes a vast amount of data and orient them to a specific purpose: the most important goal for this research was to create an 'informative' model able to link, connect and share a different type of information. In order to achieve this research objective, the proposed process involved a great team composed of BIM experts of the DABC GIcarus lab, PhD students, and one hundred students of the Polo Territoriale di Lecco of the Politecnico of Milan in the generation of the HBIM. The process had to consider the following steps:

- HBIM generation: the automatic transformation of the NURBS model in parametric HBIM objects;

- Information mapping: the link of information and the creation of new BIM parameters in order to create detailed schedules and databases;

- Information sharing: to develop a BIM cloud system in order to simplify the display of the model and its connected information.

Once created detailed NURBS elements from cleaned point clouds, it has been possible to create HBIM objects automatically. The use of GOG 9 and GOG 10 has improved the modeling of complex elements, as well as the reduction of time and cost of creation of detailed HBIM models. From an operative point of view, these new modeling requirements (GOG9-10) have also been supported by the information mapping phase. The automatic creation of HBIM objects has enabled the parametric function typical of Autodesk Revit: the association of new BIM parameters to each object. In particular, in order to certify the quality of each building component the following parameters were added: GOGs, GOA (standard deviation), new descriptive fields, new external links (https link, BIM cloud link, ...). Once the mapping phase was concluded, it has been possible to enable the automatic function for the creation of HBIM database and schedules. This specific function allowed the extraction of information, contents and parameters previously mapped within the HBIM model.

These two steps were essential for the information sharing phase. The enrichment of the model with different types of data required the model sharing to different types of users such as architects, engineers, historians, restorers, experts and non-expert BIM users. For this reason, information sharing must include a more user-friendly way of displaying the model and its information. Accordingly, thanks to the development of a cloud platform (Autodesk A360) it has been possible to share a considerable quantity of $2 \mathrm{D}$ and $3 \mathrm{D}$ data by a large selection of exchange formats such as .3ds, Collada, AutoCAD DXF and DWG, .fbx, .obj, PTS, .skp, .stl, XYZ, ... . The most important advantages of this third step were: Realtime review, 2D and 3D viewer Storage, Security, Data organisation, Access from mobile devices, Quick data search, Project metadata, and Real-time review (Fig 6). 

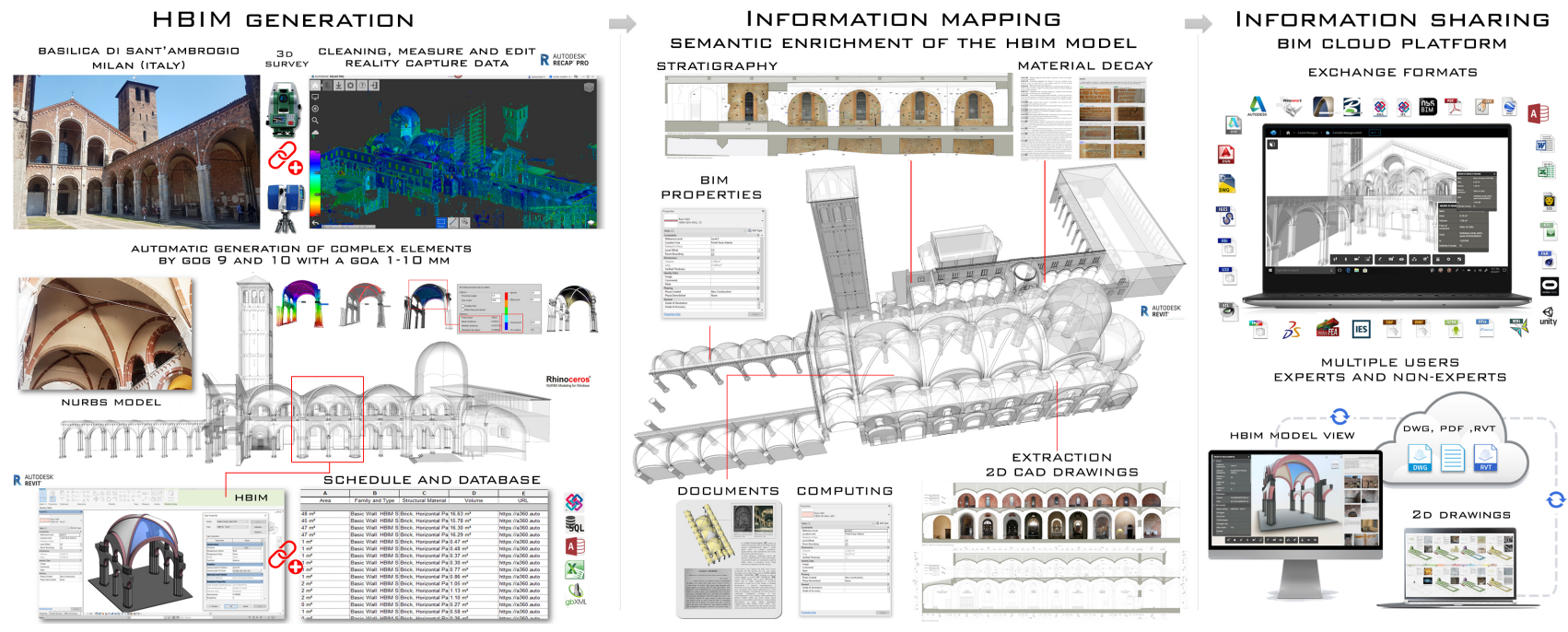

Figure 6. The three steps applied to the HBIM model: thanks to an 'informative' HBIM model and a BIM cloud platform, it has been possible to improve the level of information for the different type of users.

\subsection{A content-based immersive experience: from 3d survey to virtual reality}

Paragraph 3.3 shown how the concept of heritage in BIM has been characterised not just by the traditional, morphological, geographical, chronological concept of heritage but also by a holistic one. While initially, the generation of HBIM models tried to represent the detected reality where physical features and material information were the only parameters, other additional information has been added such as historic and artistic values, the identity and the capacity of the objects to interact with the society, its history and memory (cultural impact). In recent years, one of the main applications proposed in the field of virtual reality (VR) and augmented reality (AR) is the integration of new devices and tools such as Samsung gear, Microsoft Hololens, Oculus Rift which can bring the user to new levels of immersion in the digital model. Thanks to these innovative technological developments it has been possible to start a phase of development and experimentation in the field of $\mathrm{Xr}$ reality (Virtual and augmented reality) trying to increase the knowledge of information models through a more increased interaction between HBIM model, information and users. In order to increase the sharing of information, modeling tests and new immersive environments have been developed for the case study of the Basilica of Sant'Ambrogio in Milan, laying the foundations for multi-level information environments. The high level of information mapping obtained by the proposed generative process led to enrich the model with the intangible values of the Basilica, previously described in Stanga C. et al. A n-d virtual notebook about the Basilica of $S$. Ambrogio in Milan: information modeling for the communication of historical phases subtraction process. Conversion tests have shown how an HBIM model can be transferred among 3D modeling software and how many/which information can be transmitted during the long-life cycle of the building (LLCB). Thanks to the development and the proper orientation of new 3D gaming software it was possible to migrate the HBIM model into post-production software such as Unity and Unreal Engine, increasing the utility of BIM also for virtual museums and tourist purposes. As we well know, object and information interactivity in Unity and Unreal Engine require the user scripts. VR software provides for the use of three languages: $\mathrm{C}$
\#, Javascript and Boo. The $\mathrm{C}$ \# language is the most commonly used in Unity.

Unity scripts are all classes that inherit from Monobehavior.

A class identifies a category of objects that all have the same properties. Each class is contained within a text file, which includes all the properties of the objects of that class. It is clear that a good part of the work consists in creating the desired effect both in the modeled objects and in the VR software scripting. It often takes long generative times, which restricts the possibilities for developing. VR objects (mesh models) are characterised by a series of vertices, edges, and triangles/polygons. In particular, the vertices are points in $3 \mathrm{D}$ space; the edges (or segments) are the lines that connect them; the polygons are the surfaces that are formed when edges join 3 or more vertices. It applies to all engines and is always to be kept in mind when specifying the "polygonal resolution" of a model for video games. So, modeling tests have found that the generation of proper NURBS objects by GOG 9 and G0G 10 can better manage the number of polygons, underlining how the transformation of NURBS models into mesh models can be decisive for the generation of hyper-realistic objects, thus favouring an object interaction for the HR immersive scenes. Consequently, generative modeling and programming become vital factors for the generation of mixed reality experiences in order to achieve a strong sense of being presented in a virtual environment enriched by 'moving' objects with a high level of contents. For the case study of the Basilica, it was decided to develop a VR environment capable of being explored by different users (expert and non-experts). The following paragraphs are related to the immersive storytelling of the church that is offered through the VR experience. They are not an exhaustive history of the church (for a recent comprehensive publication on the subject see: Gatti Perrer, 1995) but reflects our 'virtual subtraction process' of the different historical phases of the church, with the aim to highlight some of the main episodes of those histories, that are included in the Virtual Reality experience of the Basilica. In fact, instead of offering traditional storytelling of the church, the research starts from the present arrangement of the Basilica, and it goes back to its foundation. 


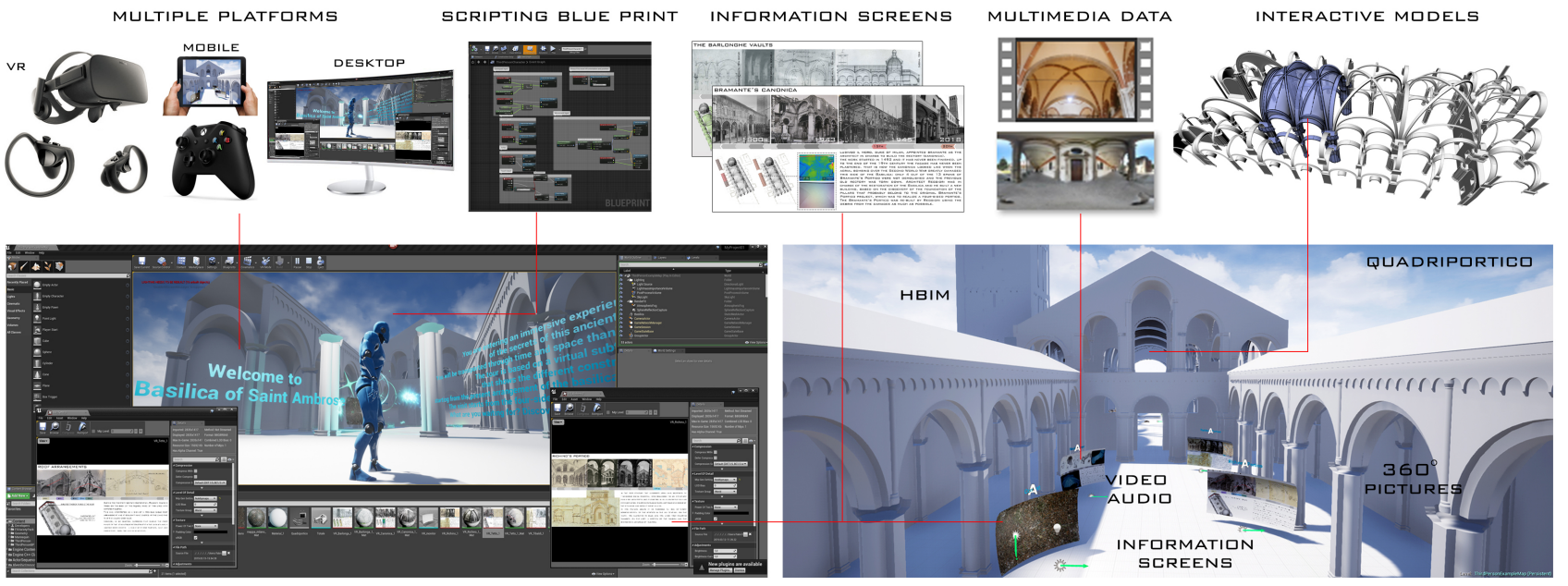

Figure 8. The Xr project has provided for the different data sources such as information screens, multimedia data and an interactive model.

\subsubsection{The restoration works before and after the Second World War}

It is almost known that the Basilica suffered significant material loss due to the aerial bombing of the Second World War (Marucci et al., 2004).

It could maybe not important to notice - but sometimes it is better to stress - that the Basilica that visitors see today is the results not only of the transformation occurred over the centuries, but also of two great events that strongly changed the appearance, and also its material substance. One is the restoration by architect Reggiori, after the 1940 s aerial bombing, and the other is the stylistic restoration promoted by the abbot of the church, Francesco Maria Rossi, in the second half of the $19^{\text {th }}$ century.

The aerial bombing (1943) particularly affected the Bramante's Canonica: only 4 spans out of 13, were not demolished. Reggiori used a 'scientific method' for the reconstruction of the destroyed parts of the Canonica, based on the study of the material remains. He tried to integrate into the reconstruction of the spans as many debrief as possible.

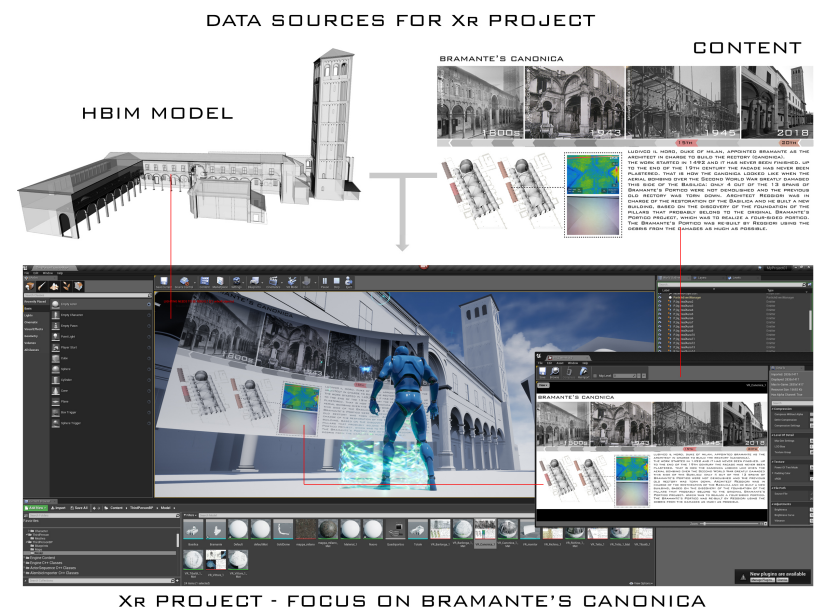

Figure 9. The HBIM model and the history of Bramante's Canonica are connected in the $\mathrm{Xr}$ project.

\subsection{The stylistic restoration in the $19^{\text {th }}$ century}

The $19^{\text {th }}$-century works were highly promoted by the abbot of the church, Francesco Maria Rossi, and many architects were involved, like Gaetano Landriani and the Alsatian architect Fernand De Dartein. The main goal of Rossi was to bring the Basilica back to its Christian origins.

The emblematic example of his work is the demolition of the Barlonghe vaults. At that time the nave of the church was characterised by two cross vaults on square plan (the two span close to the entrance) and two cross vaults on rectangular plan (close to the presbytery).

Abbot Rossi found a trace of a round arch on the wall of the nave and decided to tear down the two Barlonghe vaults and built a cross vault similar to the other existing two. Probably the two Barlonghe vaults were built around the 1193, when the previous one collapsed. The literature kept traces of this event thanks to the record of the damages occurred at the pulpit, that was and still is located in the span of the nave close to the presbytery.
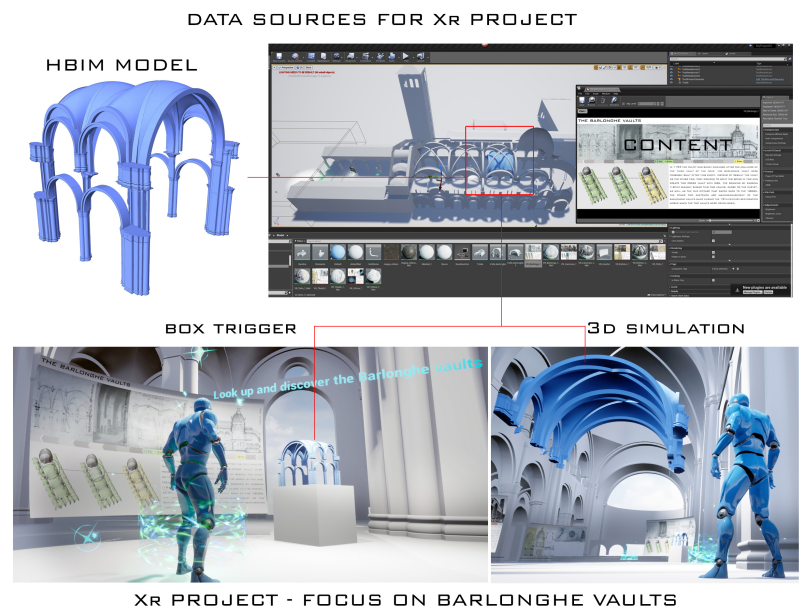

Figure 10. 3D simulation of the Barlonghe vaults in the $\mathrm{Xr}$ project. Box trigger function allows the interaction between the user and the interactive object. 


\subsubsection{From the $18^{\text {th }}$ to the $15^{\text {th }}$ century: the projects by Pellegrino, Richini and Bramante}

The $18^{\text {th }}$ to the $15^{\text {th }}$ century are characterised by great changes into the architecture of the Basilica Three of the greatest architects in Milan were involved in its transformations: Francesco Maria Richino, Pellegrino Tibaldi and Donato Bramante.

The pastoral visits of Carlo Borromeo in 1566 and 1578 recorded the bad state of conservation of the church: Pellegrino Tibaldi was in charge of the restoration of the cupola: he realised a cassettonato decoration and four angels, that were placed at the four squinches of the cupola. His work was removed during the $19^{\text {th }}$-century restoration.

In the $17^{\text {th }}$ century, there were two pastoral visits by Federico Borromeo: Francesco Maria Richino was in charge of the restoration of the four-sided portico. He developed many projects, which are still preserved in the collection of drawing 'Raccolta Bianconi' at the Castello Sforzesco in Milan (Fig. 11).

Ludovico il Moro commissioned to architect Donato Bramante the project of the Canonica, that was realised between 1492 and 1499: from this time on the northern side of the Basilica will be characterised by this great architecture, which hidden another great structure as well - the double-waved curve wall.

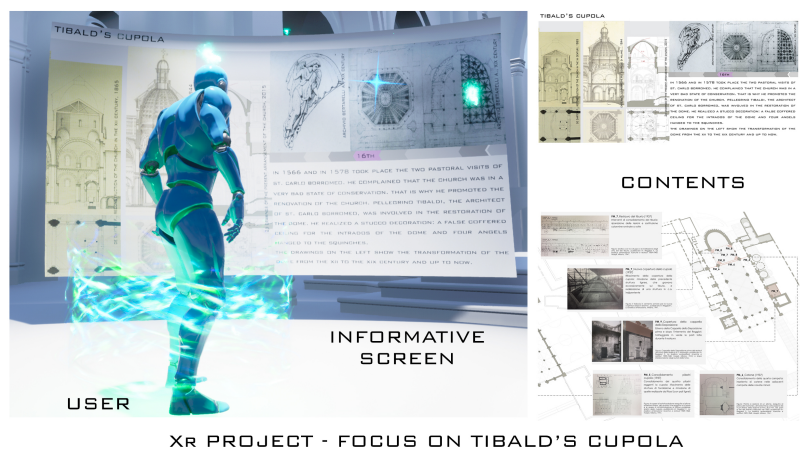

Figure 11. Thanks to the informative screen it is possible to interact with the model and its unique and historical contents.

\subsubsection{The Romanesque reconstruction between the $13^{\text {th }}$ and $11^{\text {th }}$ centuries}

For the architect who worked during the $19^{\text {th }}$-century restoration, the vaulted system of the Basilica was built during the 'Romanesque reconstruction': the $4^{\text {th }}$-century church was probably covered by a wooden roof, and it was from the $11^{\text {th }}$ century (scholars do not all agree on this date) that vaults had been built.

Related to the Romanesque reconstruction and in a certain way, to the vaulted system construction, there is an interesting structure, not very well known by the visitors of the church, and not studied that much by scholars, which is the doublewaved curve wall with its arches and pillars. The arches connect the pillars (buttresses) on the northern and southern walls of the church: the ones of the southern wall are not well visible and accessible because they are integrated with the roof systems of the side chapels.

The northern one, easily accessible, are hidden behind Bramante's Canonica but are visible at the level of the first storey of the Canonica. This part was highly investigated thanks to a photogrammetric survey, which implemented the VR project of this side of the church (Fig 12).

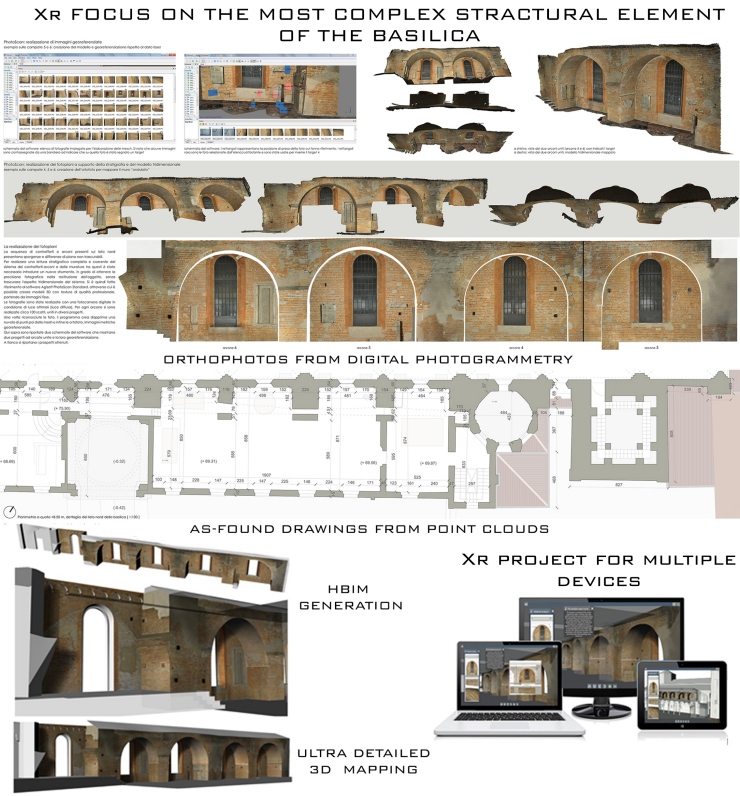

Figure 12. The Xr contents related to the focus of the doublewaved curve wall: different data sources have been used for a detailed 3D mapping in Unreal Engine 4.

3.4.6. Hypothesis about the former church, founded by Archbishop Ambrogio in the late $4^{\text {th }}$ century

The history of the church now goes back to its foundation. It was founded in the late $4^{\text {th }}$ century by Archbishop Ambrogio on a former funerary area (Lusuardi Siena, 1997). S. Vittore in Ciel d'Oro chapel is probably the most known part of the first arrangement of the Basilica. S. Vittore is a small square chapel, with a crypt, covered by a cupola. The cupola is made of tubi fittili (clay elements), a light-construction technique (Brumana, 1990). The cupola and partially the walls are covered by mosaics (late $4^{\text {th }}-5^{\text {th }}$ century): a golden sky and blue walls. On the walls, among the martyrs Gervasio and Protasio, Nabore and Felice, there are the Milanese archbishops Materno and Ambrogio. The VR project shows one of the oldest representations of Ambrogio (young) and the richness of the shapes of this unique structural element.

The $\mathrm{Xr}$ project has been developed for different types of devices, from the VR Headsets to the mobile phone, in order to make it easily available to the final users (Fig. 13).

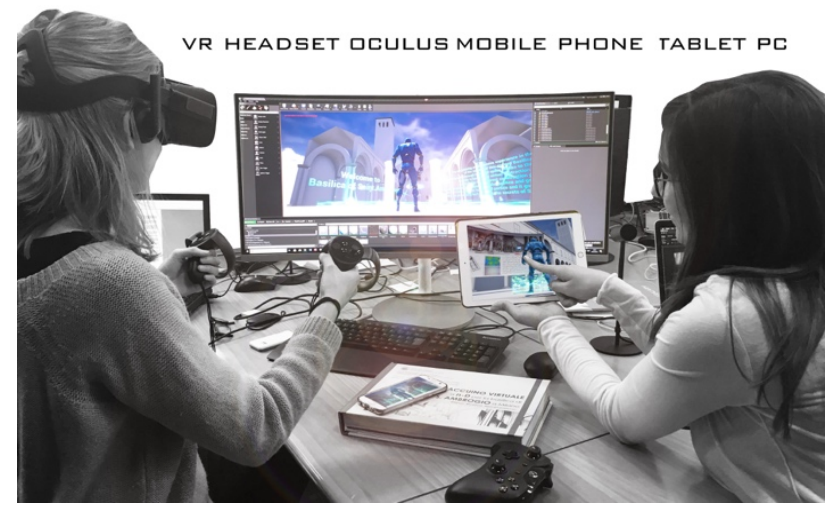

Figure 13. Xr project is developed for the different type of devices. 


\section{RESULTS AND CONCLUSIONS}

The Virtual Reality experience is the last step of the holistic approach that involves different disciplines. It is the natural result of the previous phases: the 3D survey and modeling, the historical research and Building Archaeology analysis were fundamental for the realisation of an immersive discovery of the Basilica through time and space. The VR experience offers a tour where the visitor can easily virtually walk through the church and have a look at its structures. The digital information screens that are placed in specific locations guide the visitor and give knowledge pills about the history of the Basilica. At the same time, they reveal hidden aspects, as in the case of the Barlonghe vaults, which appear to the visitor showing a previous arrangement of the church. The "virtual subtraction process' raise the awareness to look at the church not as a building with a coherent design, but as a palimpsest, the results of different construction phases.

The great amount of collected data makes this research an ongoing process and also the VR experience can be implemented with additional studies or customise for different purposes. Further developments will implement the Augmented Reality experience in order to have the possibility to interact at the same time both with the virtual and the real environment. It can also help restorers and researchers in their studies, allowing to take notes on the tablet while visiting the church, making the specific analysis as well (i.e. material decay analysis, structural assessment, ...).

\section{ACKNOWLEDGEMENTS}

Data from surveying, modeling, HBIM generation, interpretation and communication of the Basilica di Sant'Ambrogio in Milan have been provided and supported by the on-course GAMHer project: Geomatics Data Acquisition and Management for Landscape and Built Heritage in a European Perspective, PRIN, Progetti di Ricerca di Rilevante Interesse Nazionale - Bando 2015, Prot. 2015HJLS7E. (Sc. Res. POLIMI Unit R. Brumana), with the contribution of Fabrizio Banfi (GEO) and Chiara Stanga (RES).

Thanks to Cailen Pybus, Adam Weigert and Miquel Reina Ortiz for their help creating with documentation and photogrammetry of the site.

\section{REFERENCES}

Agnello, F., Avella, F., Agnello, S., 2019. Virtual Reality for Historical Architecture. In: The International Archives of the Photogrammetry, Remote Sensing and Spatial Information Sciences, XLII-2/W9, 9-16.

Amore, R., 2017. Beni culturali e nuove tecnologi. In: Prescia R. (eds), RICerca/REStauro - sezione 4 - Valorizzazione e gestione delle informazioni, 849-856.

Aveta, A., Marino, B. G., Amore, R., 2017. Materia e realtà storica: catturare la trasformazione. Un approccio transdisciplinare per la conservazione. In: ANANKE, speciale Geores, 30-36.

Banfi, F., 2017. BIM orientation: grades of generation and information for different type of analysis and management process. In: International Archives of the Photogrammetry, Remote Sensing \& Spatial Information Sciences, 42.
Banfi, F., Previtali, M., Stanga, C., Brumana, R., 2019. A Layered-Web Interface Based on HBIM and $360^{\circ}$ Panoramas for Historical, Material and Geometric Analysis. In: International Archives of the Photogrammetry, Remote Sensing and Spatial Information Sciences, 42(2/W9).

Brumana, R., Condoleo, P., Grimoldi, A., Banfi, F., Landi, A. G., Previtali, M., 2018. HR LOD based HBIM to detect influences on geometry and shape by stereotomic construction techniques of brick vaults. In: Applied Geomatics, 1-15.

Brumana, R. 1990. Sant'Ambrogio's Basilica in Milan. A study on photogrammetric surveys in the S. Vittore in Ciel d'Oro's dome. In: Close-Range Photogrammetry Meets Machine Vision, 1395, 908-915.

Cacudi, G., 2018. La fruizione multimediale del Castello di Lecce. In: Marotta A., Spallone R. (eds), Defensive architecture of the mediterranean, vol. 9, 1157-1164.

Falk Anderson, E., McLoughlin, L., Liarokapis, F., Peters, C., Petridis, P., de Freitas, S., 2009. Serious Game in Cultural Heritage. In: Ashley M. and Liarokapis F. (eds), The 10th International Symposium on Virtual Reality, Archaeology and Cultural Heritage.

Gatti Perer, M. L., 1995. La basilica di S. Ambrogio: il tempio ininterrotto, vol. 1-2. Milan: Vita e Pensiero.

Lusuardi Siena, S., 1997. "Ambrogio, il costruttore sapiente”. In: La città e la sua memoria: Milano e la tradizione di Sant'Ambrogio, edited by Marco Rizzi, Cesare Pasini, Maria Pia Rossignani, 34-35. Milan: Electa.

Marucci, R. A., Negri, M., Rastelli, A. Romaniello, L., 2004. Bombe sulla città: Milano in guerra 1942-44, 236-240.

Mortara, M., Catalano, C. E., Bellotti, F., Fiucci, G., HouryPanchetti, M., Petridis, P., 2014. Learning cultural heritage by serious games. In: Journal of Cultural Heritage, Elsevier, 15(3), 318-325.

Ortega, M. D. R., Alvarado, L. O., Higueruela, F. R. F., 2015. Advances in 3D Spatial Information Systems. Applications in cultural heritage and virtual archaeology. In: Virtual Archaeology Review, 6(12), 77-91.

Stanga, C., Spinelli, C., Brumana, R., Oreni, D., Valente, R., Banfi, F., 2017. A n-d virtual notebook about the basilica of S. Ambrogio in Milan: information modeling for the communication of historical phases subtraction process. In: International Archives of The Photogrammetry, Remote Sensing \& Spatial Information Sciences, 42, 653-660.

Statham, N., 2019. Scientific rigour of online platforms for 3D visualization of heritage. In: Virtual Archaeology Review, 116.

Tucci, G., Bonora, V., Fiorini, L., Conti, A., 2016. The Florence baptistery: 3-D Survey as a knowledge tool for historical and structural investigations. In: International Archives of the Photogrammetry, Remote Sensing and Spatial Information Sciences, 41, 977-984. 